\title{
Reappraisal of the chloride plate test as screening test for cystic fibrosis
}

\author{
HARRY SHWACHMAN AND ABBAS MAHMOODIAN
}

Children's Hospital Medical Center, and Department of Pediatrics, Harvard Medical School, Boston, Massachusetts, USA

SUMMARY A rapid and simple screening test for detecting cystic fibrosis, described in 1956, has been used routinely for 21 years; the results during a 15 -month period are compared with those using the quantitative pilocarpine iontophoresis sweat test. In the chloride agar plate test the concentration of chloride on the finger tips is evaluated according to the intensity of the imprint. Readings of $2+$ or less excluded cystic fibrosis in 1589 cases with only two doubtful instances, whereas $4+$ readings were recorded in 198 cases of cystic fibrosis and $3+$ readings in 15 cases of cystic fibrosis. In doubtful cases 4 individuals had $4+$ readings and 11 had $3+$ readings. This screening test does not replace the quantitative pilocarpine iontophoresis test but it does identify an individual who is likely to have the disease and who requires further tests. It is not reliable for infants aged under 2 months.

The diagnosis of cystic fibrosis (CF) is based on the accurate determination of sweat electrolytes under standard conditions in patients with clinical features of the disease. The quantitative pilocarpine iontophoresis (QPI) technique of Gibson and Cooke is the recommended sweat test procedure. ${ }^{1}$ The purpose of this paper is to report our experience with a simple screening test first described in $1956 .^{2}$ It seems appropriate to reappraise the procedure after 22 years of daily use. This screening test is not meant to replace the quantitative analysis but it can identify an individual who is likely to have the disease. If a screening test is to be of use it should have a high degree of specificity and sensitivity, it should be inexpensive, require little time, and be simple. The chloride plate test fulfils these criteria.

Since the report of Shwachman and $\mathrm{Gahm}^{2}$ we have modified the readings by grouping them into four categories, rather than three, in an attempt to have a better refinement of the interpretation. Each year for the last 20 we have performed about 1200 QPI sweat tests. We specify the amount of sweat collected and the concentration of sodium, potassium, and chloride in $\mathrm{mEq} / \mathrm{l} /(\mathrm{mmol} / \mathrm{l}) .{ }^{3}$ The chloride plate test was used as well. (Others have modified the original method by using impregnated filter paper in place of the agar plate. ${ }^{4-6}$ )

The fingertips are applied for about 2 seconds with very light pressure, and the imprint is noted immediately. The intensity of the white imprint against the dark background is a reflection of the amount of chloride on the skin. The entire hand or foot of an infant can be imprinted. Fig. 1 shows the various grades, progressing from a $1+$ reading on the left to a $4+$ reading on the right.

A healthy infant under 8 weeks of age generally does not leave an imprint. Thus, if a 2 -week-old infant gave a $1+$ or $2+$ reading, this would be a significant observation since most healthy babies of this age would leave no marks. Some healthy adults may give $3+$ readings. The concentration of chloride on the fingertips does not parallel that on the body. Stress or emotional stimulation increases the sweat rate and electrolyte concentration on hands, but not on the body. Evaporation of water also increases the concentration. Some conditions may distort the true reading-for example, the child sucking his fingers before the test may remove the chloride, as does the child who washes his hands, or goes to the fountain for a drink. A false-positive test may result if the child has eaten salted peanuts or dipped his hands in salted foods. The temperature of the air should also be considered. A child entering the room from the cold outdoors may require a 30-minute warm-up period before testing. It is prudent to watch the patient for at least 20 minutes before performing the test. It takes about 20 minutes for the sweat to reaccumulate should one wish to repeat the test, after washing the hands. Should the reading be equivocal the test can be repeated on the same day or later. If in doubt, or if the test gives a positive result the standard QPI sweat test should be done. 


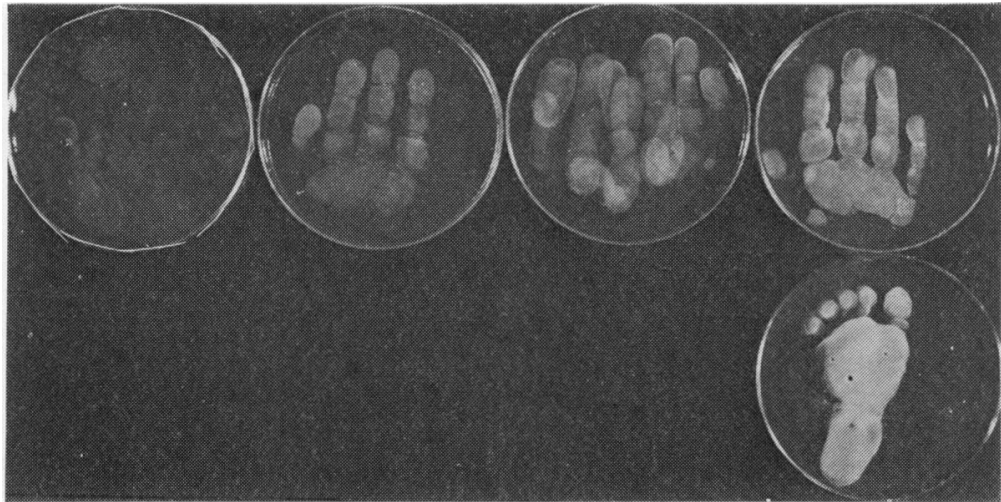

Fig. 1 Chloride plate imprints. Readings from left to right, grade $1+$ to grade $4+$. On the bottom right is a foot imprint of a 10-week-old baby with cystic fibrosis (sweat chloride was $74.0 \mathrm{mmol} / \mathrm{l}$ ).

MacFarlane et al. ${ }^{7}$ tested our method; 54 patients with known CF gave a $3+$ reaction, and after washing the hands and waiting a full 20 minutes all patients still gave a $3+$ reaction. In a series of about 200 'normal' children of the same age group tested as controls, no false-positives were encountered. MacFarlane $e$ e al. ${ }^{7}$ found a 3 + reaction as early as age 4 weeks in an infant known to have CF.

Catzel $^{8}$ tested 230 patients between 3 months and 12 years of age and found no false-positives. This group included 17 children with kwashiorkor of whom only 2 gave $2+$ reactions. He confirmed that if the hands are washed and dried a period of 20 minutes is needed before the test can be reliably repeated. Geissler ${ }^{9}$ found 10 positive reactions, 9 in patients with confirmed CF, out of 300 experiments with the finger-print test. In the tenth case the patient had bronchiectasis with increased sweat electrolytes and normally functioning pancreas, and Geissler considered that the patient had partial pancreatic fibrosis. She considered the test accurate and recommended its use. Vavrova ${ }^{10}$ also confirmed the value of the test as he did, too, of a spot test described by Shwachman and Antonowicz.11

It is clear that the chloride plate test cannot be used as a screening test in the newborn period.

We have previously suggested that meconium should be tested for albumin ${ }^{12}$ as a screening test in the neonate, and this led to the development of a paper strip test ${ }^{\mathbf{1 3}}$ however this test was not recommended by the Cystic Fibrosis Foundation as a test to be used routinely, as a result of a collaborative study. ${ }^{14}$ We have now developed a new approach to screening the newborn based on the increased viscosity of meconium (L Kopito and H Shwachman, personal communication).

\section{Results}

Over a 15 -month period a total of 1896 chloride plate tests were performed at the same time as a QPI test. All patients were referred for diagnostic purposes. We felt that this sample number of tests (approximately $10 \%$ of our data) would suffice to demonstrate the value of this method of screening. Patients with CF, and some doubtful cases, were tested twice with few exceptions. The age range of these patients was 2 days to 60 years, with $90 \%$ of tests on patients under 25 years of age. There was an equal sex distribution. 48 tests performed on babies under 2 months are not shown in the Table, since none left a visible imprint not even 2 infants with CF aged 28 and 30 days (Table and Fig. 2). All 48 infants were success-

\section{Table 1848 chloride plate test results}

\begin{tabular}{lrrr}
\hline Reading & \multicolumn{2}{c}{ Cystic fibrosis } & Borderline or doubtful \\
\cline { 2 - 3 } & Yes & No & \\
\hline $4+$ & 198 & 0 & 4 \\
$3+$ & 15 & 31 & 11 \\
$2+$ or less & 0 & 1589 & 2 \\
\hline
\end{tabular}

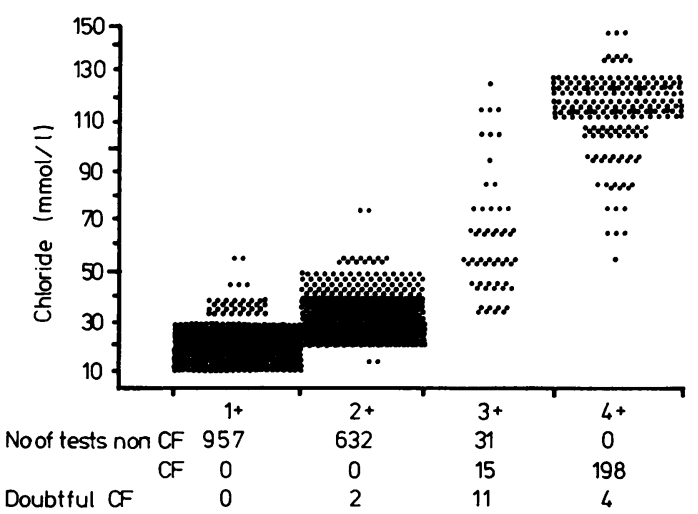

Fig. 2 Chloride values ( $\mathrm{mEq} / \mathrm{l} / \mathrm{mmol} / \mathrm{l})$ obtained by the $Q P I$ method compared with the readings made by the chloride plate method. 
fully sweat tested by the QPI method. However, one 8 -week-old baby with CF gave a $3+$ reaction and another at 10 weeks gave a $4+$ reading. One infant with $\mathrm{CF}$ at 8 days gave a 2 + reading and the quantitative sweat test was $70 \mathrm{mmol} / \mathrm{l}$ for chloride.

Of the 957 patients who gave a $1+$ reaction, the chloride concentration by the QPI technique was $<60 \mathrm{mmol} / \mathrm{l}$ in all cases (Fig. 2). Of the 632 individuals with a $2+$ reaction only two values were in the lower $\mathrm{CF}$ range. These two readings were made on one patient who did not have sufficient clinical evidence for the diagnosis of $\mathrm{CF}$.

57 reactions on the chloride plate were $3+$. Of these, 31 were not from patients with CF. 11 were from patients in whom the diagnosis was questioned and whose chloride values by the QPI method were between 55 and $70 \mathrm{mmol} / \mathrm{l} .15$ reactions of $3+$ were from 15 patients with $C F$.

Of the $4+$ reactions, all but 4 were made by patients with fully established CF. These 4 exceptions were patients with typical pulmonary manifestations of $\mathrm{CF}$, normal pancreatic function, and borderline values by the QPI method on more than three separate occasions. We consider they have CF but that it is not fully expressed..$^{15-16}$

\section{Conclusions}

(1) The chloride agar plate gave a reading of $2+$ or less in 1589 tests on patients who did not have CF as determined by clinical and by a QPI sweat test. Certain precautions in the performance of the test have been given.

(2) All patients with proved CF gave a $3+$ or $4+$ reaction.

(3) The test has limited value in babies under 2 months of age.

(4) The test is simple, instantaneous, and inexpensive with sensitivity of $100 \%$ and specificity of over $95 \%$.

(5) This screening test does not replace any of the sound techniques of quantitating the concentration of sodium and chloride.

(6) All patients in whom the diagnosis of CF is made should have at least two separate QPI sweat tests.

\section{Appendix}

The plates are currently made up as follows:

One litre will yield 60 plates. The ingredients are: $6 \mathrm{~g}$ silver nitrate, $3 \mathrm{~g}$ potassium chromate, and $60 \mathrm{~g}$ agar.

The chemicals in solution are gradually added to the heated agar in solution while stirring to a final volume of 1 litre with water. The plates are poured while hot. After reaching room temperature they are placed inverted in the refrigerator where they are stored until needed. The life of a plate is about 8 weeks since they tend to dry out with storage.

This study was partly supported by the Ina Sue Perlmutter Fund, the Jeffrey Moss Fund for the Study of Cystic Fibrosis, and the Cystic Fibrosis Foundation.

\section{References}

1 Gibson L E, Cooke R E. Guide to diagnosis and management. Maryland: National Cystic Fibrosis Research Foundation, 1963: 21.

2 Shwachman H, Gahm N. Studies in cystic fibrosis of the pancreas. A simple test for the detection of excess chloride on the skin. $N$ Engl J Med 1956; 255: 999-1001.

3 Shwachman H, Mahmoodian A. Pilocarpine iontophoresis sweat testing. Results of seven years' experience. Mod Probl Paediatr 1967; 10: 158-82.

4 Takahashi $Y$, Wada $M$. The permanent recording of sweat by plastic impression. J Invest Dermatol 1962; 38: 197-8.

5 Fortina A. Modified Shwachman test for the diagnosis of mucoviscidosis (in Italian). Minerva Pediatr 1961; 13: 1286-7.

6 Knights E M, Jr, Brush J S, Schroeder J. Simplified screening test for detecting cystic fibrosis of the pancreas. JAMA 1959; 169: 1279-80.

7 MacFarlane J C W, Norman A P, Stroud C E. Fingerprint sweat test in fibrocystic disease of pancreas. $\mathrm{Br} \mathrm{Med}$ $J$ 1957; ii: 274-5.

8 Catzel P. The finger-print sweat test. $S$ Afr Med J 1950; 32: 325-7.

9 Geissler J. On experiences with the finger-print test in pancreatic fibrosis (in German). Munch Med Wochenschr 1959; 101: 1978-82.

10 Vavrova $V$. The imprint test in screening for mucoviscidosis (in Czechoslovakian). Cesk Pediatr 1965; 20: 16-22.

11 Shwachman H, Antonowicz I. Problems in cystic fibrosis. The sweat test in cystic fibrosis. Ann NY Acad Sci 1962; 93: $600-20$.

12 Green M N, Shwachman H. Presumptive test for cystic fibrosis based on serum protein in meconium. Pediatrics 1968; 41 : 989-92.

13 Stephan U, Busch E W, Kollberg H, Hellsing K. Cystic fibrosis determination by means of a test strip. Pediatrics 1975; 55: 35-8.

14 Holsclaw D, Keith H, Palmer J. Meconium screening for cystic fibrosis. Pediatr Ann 1968; 7: 29-40.

15 Shwachman H, Goodchild M C, Khaw K T, Kopito L, Mahmoodian A. Incomplete expression of cystic fibrosis (abstract). Rockville, Maryland: National Cystic Fibrosis Research Foundation, 1966.

16 Stern R C, Boat T F, Abramowsky C R, Matthews L W, Wood $R$ E, Doershuk C F. Intermediate-range sweat chloride concentration and Pseudomonas bronchitis. JAMA 1978; 239: 2676-80.

Correspondence to Dr Harry Shwachman, Children's Hospital Medical Center, 300 Longwood Avenue, Boston, Massachusetts 02115, USA.

Received 25 September 1979 